\title{
PECULIARITIES OF SENSATION, PERCEPTION AND EMOTIONAL FUNCTIONING DISORDERS IN PATIENTS WITH SCHIZOPHRENIA AND OBESITY
}

\author{
Oprya Ye.
}

\author{
Odesa National Medical University, Ukraine
}

\begin{abstract}
The article presents the results of clinical and psychopathological study of the presence and peculiarities of emotional disturbances, perception and functioning of the emotional sphere in patients with schizophrenia and obesity. The study involved examination of 44 patients previously diagnosed with schizophrenia and obesity in a comparative aspect with patients with schizophrenia but without obesity and other concomitant somatic pathology (50 patients). It has been established that the combination of obesity with schizophrenia is characterized by a certain specific sensation disorder, perception and emotional functioning, manifested by the presence in the clinical picture of schizophrenia senestopathy and complex hallucinations (which along with auditory and visual hallucinations also include visceral hallucinations and hallucinations of the skin sensation), rigidity of emotional reactions, the presence of distinct emotional disturbances of the depressive spectrum and dysphoric mood disorders.
\end{abstract}

Key words: schizophrenia, obesity, sensation and perception, emotional disturbances.

Introduction. Excessive body weight and obesity in patients with mental disorders is a complex problem of modern psychiatry. Especially often overweight is registered in patients with schizophrenia, which according to clinical studies is observed in more than $60 \%$ of patients [5]. The reasons for the high prevalence of obesity among schizophrenia patients are seen in the features of the disease itself, including the decrease in physical activity due to prolonged hospitalizations, negative symptoms, the decline in the social and economic status of patients, the peculiarity of neurohumoral processes, carbohydrates metabolism, as well as the effects of prolonged antipsychotic therapy $[1,5,6,10]$. The specific danger of excessive weight is in increasing the risk of developing cardiovascular diseases, stroke and heart attacks, diabetes mellitus and cancer, which are the main causes of premature mortality of schizophrenic patients $[2,3,8,9]$. In addition, obesity affects the selfesteem of patients, leads to stigma, a decrease in

Corresponding Author:

Yevgen Oprya, MD, PhD, Associate professor of the Department of Psychiatry and Narcology, Odesa National Medical University, Ukraine E-mail: yoprya@yahoo.com social activity, and is one of the leading factors of stop or non-compliance in maintenance antipsychotic therapy.

Recently, special attention is paid to the factors and mechanisms of obesity formation in schizophrenic patients, the effects of psychotropic drugs on body weight are also actively studied, as well as large-scale biochemical studies of the carbohydrate-lipid metabolism of schizophrenia patients are being conducted, which prove that obesity and schizophrenia are closely interconnected with each other and can be both a precondition and outcome of each other [5, 7]. Taking into consideration that obesity is a multisystem disease, special attention should be paid to the issue of presence and specificity of clinical pathomorphism of manifestations of schizophrenia in case of its combination with obesity, which exactly predetermined the purpose of the proposed study.

2. Purposes, subjects and methods:

2.1. Purpose - to investigate the presence and peculiarities of emotional disturbances, perceptions and emotions disorders in the clinical structure of schizophrenic patients with obesity.

2.2. Subjects \& Methods. Clinical and psychopathological examination using the clinical scale of positive and negative symptoms (Positive and Negative Syndrome Scale - PANSS) [4]. 
The study involved 94 patients with schizophrenia (F20), of whom 44 schizophrenic patients with diagnosed obesity comprised the main study group, the control group included 50 schizophrenic patients without chronic somatic pathology.

Inclusion criteria in the study were as follows: the presence of a verified diagnosis of schizophrenia (F20) in accordance with ICD-10 criteria for a duration of at least 3 years; age of the patients from 18 to 60 years old; the ability of patients to participate in the study, adequately understand the requirements and instructions being presented in accordance with the research objectives and signed informed consent to participate in the study. Exclusion criteria were the presence of organic diseases of the central nervous system; moderate cognitive and psychopathological disorders that complicate the learning and performance of instructions; and in post-schizophrenic depression (F20.4).

The main group of the study was formed taking into account the presence of obesity in the patient (the body mass index (BMI) was $\geq 30$ ). The criteria for patients of the control group were the absence of chronic somatic diseases and, in particular, absence of obesity.

In the main group of patients, the majority of individuals had the first degree of obesity (BMI = $30-35)-25$ persons (59.52\%), the second degree of obesity (BMI $=35-40)$ was diagnosed in 13 persons (30.95\%), and the third degree of obesity (BMI> 40) was observed in 4 persons (9.52\%).

By gender and age, the patients of the research groups did not differ significantly, however, there was a tendency for larger amount of female subjects among patients in the main group (66.67\%), compared with patients in the control group, where the number of female subjects was $52 \%$. The average age of the observed patients in the main group of patients was 37.4 years, and in patients of the control group36.8 years.

Conflict of interests. There is no conflict of interests.

3. Results and discussion. Among the forms of schizophrenic disorder, paranoid schizophrenia predominated in both research groups: $62.4 \%$ of the patients in the main group and $78 \%$ of the patients in the control group. But it should be noted that other forms of schizophrenia were diagnosed more frequently in patients of the main group (38.6\% of cases) than among patients in the control group - in 22\% of cases, at $ð \leq 0.04$. However, data regarding the prevalence of specific forms of schizophrenia in obesity have not been revealed in this study. According to the type of schizophrenic disorder, statistical differences between the two study groups were not detected.

According to the results of the clinical examination, $81.2 \%$ of the patients in the main and $72 \%$ of the control group were diagnosed with sensation and perception disorders. The structure of the revealed disorders and their representation in the patients in the study groups is shown in Figure 1.

In the observed patients of both groups, hallucinations were the most common among sensory and perception disorders, which were revealed in $40.91 \%$ of patients in the main group and $44 \%$ of patients in the control group. At the same time, patients of the main group were significantly more often found to have senenstopathy (36.36\%), compared to patients of the control group (20\%), with $\mathrm{p} \leq 0.05$. The senestopathic sensations of the patients in the main group had a different localization, but more often they were located in the stomach (adhesion, dryness, sensation of gut pulsation, distortion, some kind of stir, pressure on internal organs, etc.), chest and head (in the form of pressure, tension, heartburn, transfusion, sticking, itching and moving in the brain, etc.) were described by the patients as unpleasant, difficult feelings, but mostly without painful interpretation, while the paroxysms were accompanied by anxiety, hypohondric delusional interpretation.

Instead of visceral hallucinations, the senestopathic sensations, despite the unusual and bizarre descriptions, were not clear and not specified. Often, senestopathic symptoms were combined in parallel with hallucinatory or sensation disorder in the form of hyperesthesia or hypesthesia.

According to the results of the research, there were no reliable differences in the representation and severity of hallucinatory behavior in patients of the studied groups. Thus, hallucinations in the structure of psychotic symptoms were noted in $40.91 \%$ of patients in the main group and their severity on the PANSS scale was $3.8 \pm 0.14$; and in $44 \%$ of patients in the control group with severity of $3.42 \pm 0.18$. At the same time, in the structure of detected hallucinations in the two studied groups it was revealed, that in patients of the main group by the level of complexity complicated (complex) hallucinations were more commonly revealed, including several analyzers 


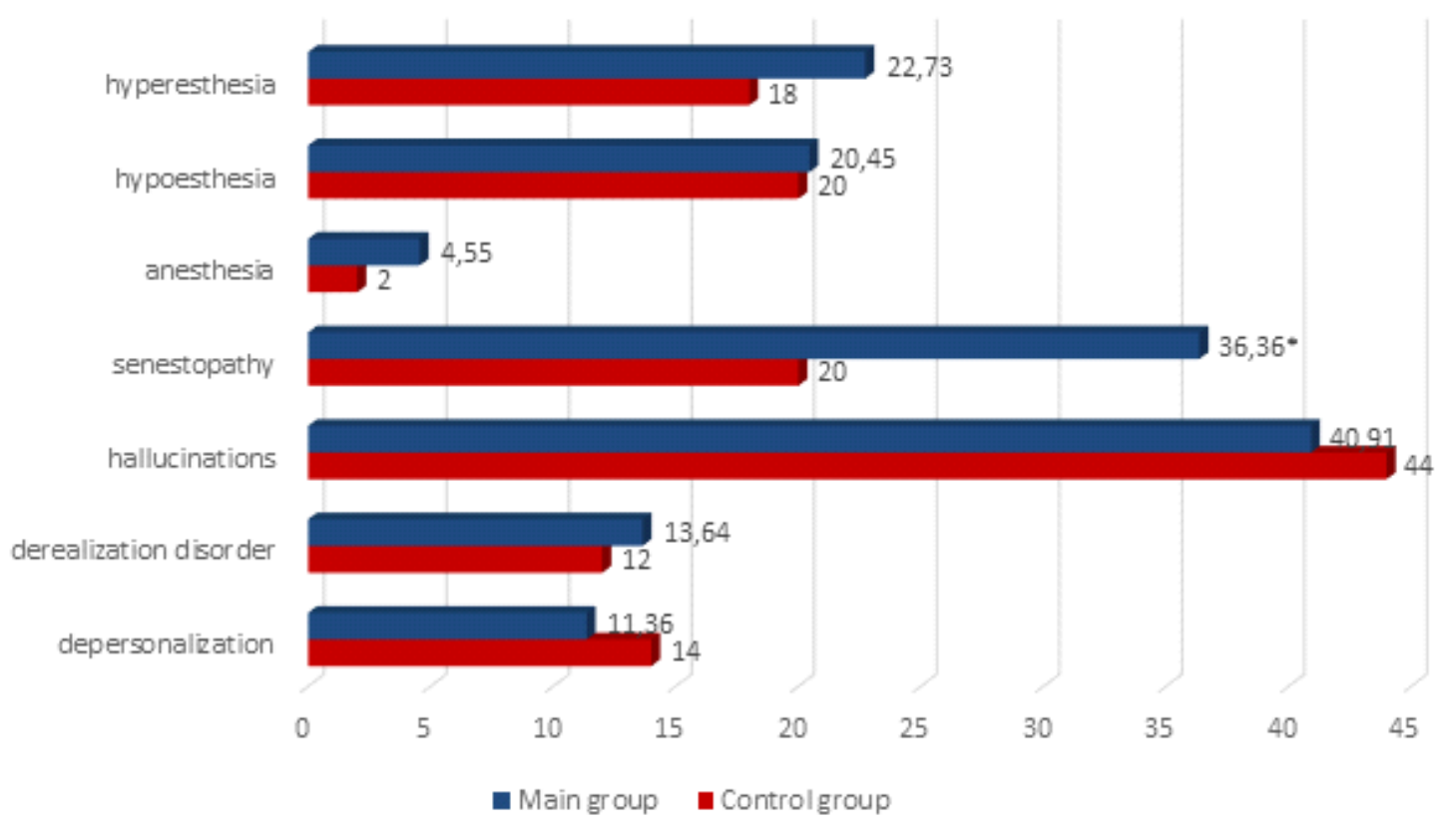

Fig. 1. Disorder of sensations and perception in the examined patients Notes: statistically significant probability indices are indicated by * $(p \leq 0.05)$

simultaneously ( $67 \%$ of the total number of patients with hallucinations per group), which in proportions to simple hallucinations were $3: 1$, while the same proportion in patients of the control group was 1.5:1 (fig. 2).

The structure of hallucinations of the patients in the main group by analyzers was presented more diverse, among the most commonly detected were auditory (27\%), visceral (22\%), skin sensation (16\%) and visual (16\%) hallucinations (fig. 3). In the same hallucinations structure of the control group, the auditory (49\%) and visual (21\%) hallucinations were significantly superior.

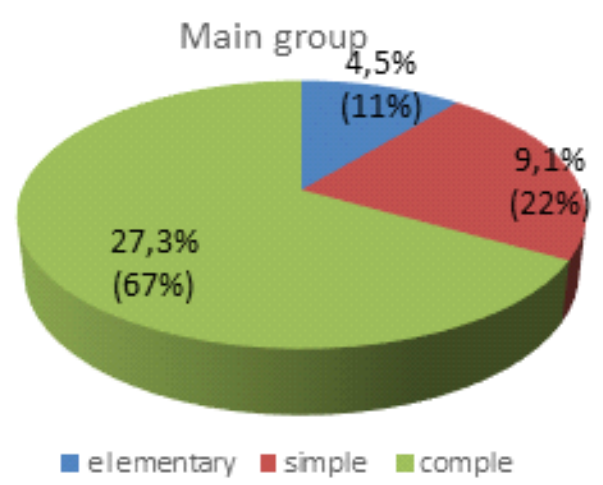

According to the type of projection in the hallucination structure of patients of both research groups, no differences were noted between the compared groups, in the hallucinatory disorders of patients of both groups, the prevalence of true hallucinations was observed (67\% of the total number of patients in the main group with hallucinations and $64 \%$ of the total number of patients in the control group with hallucinations) over the false hallucinations (33\% and 36\%, respectively) (fig. 4).

Overall, assessment of sensation and perception disorders in the clinical picture of

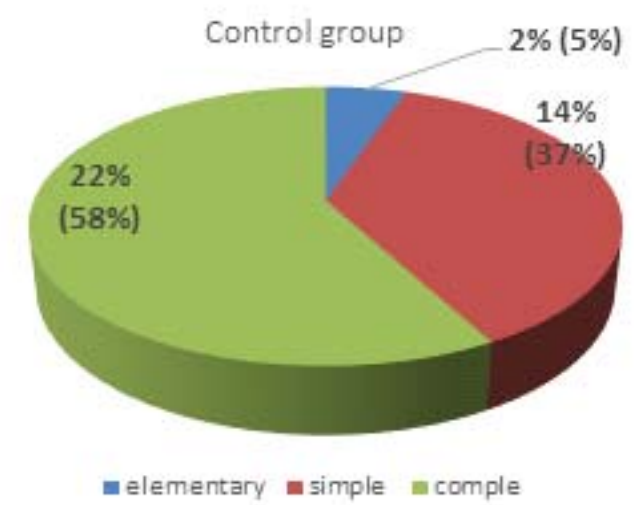

Fig. 2. Structure of detected hallucinations by degree of complexity in patients in study groups Notes: data are presented in the format: percentage of the total number of patients examined by the study group and in brackets - the proportion of the number of patients with hallucinations in the clinical picture 

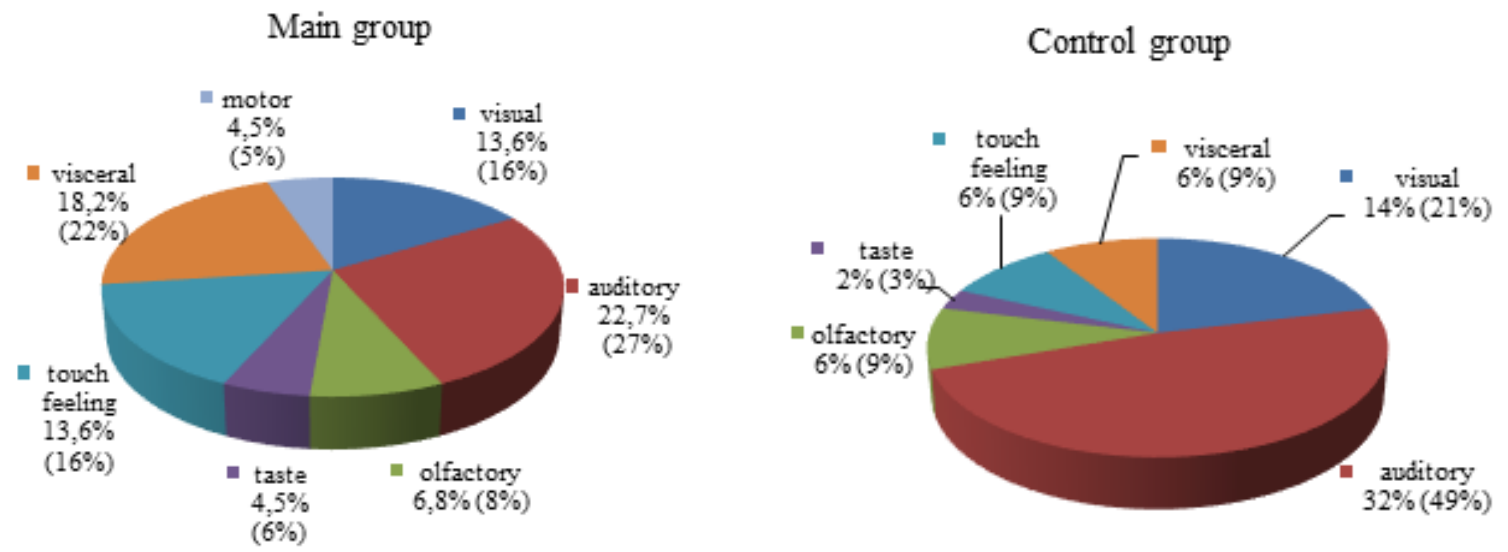

Fig. 3. The structure of detected hallucinations by analyzers in patients in study groups Notes: data are presented in the format: percentage of the total number of patients examined by the study group and in brackets - the proportion of the number of patients with hallucinations in the clinical picture

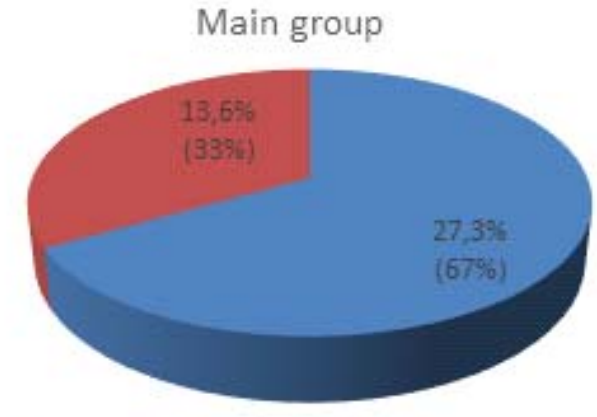

n truehallucinations false hallucinations

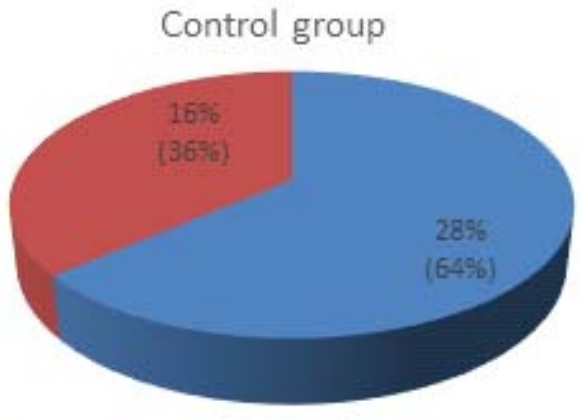

n truehallucinations false hallucinations

Fig. 4. Structure of detected hallucinations by type of projection (perception mechanism)in patients in study groups

Notes: data are presented in the format: percentage of the total number of patients examined by the study group and in brackets - the proportion of the number of patients with hallucinations in the clinical picture

schizophrenia in obese patients showed more cases of senestopathy and complicated hallucinations, among which, in addition to auditory and visual hallucinations, visceral hallucinations and hallucinations of the sensory perception more often were detected.

Emotional disorders in the form of disorders of emotional reactions and mood disorders were detected in $100 \%$ of the patients who participated in the study. The pathology of emotional reactions in patients of both groups in the overwhelming majority was represented by deficiency (flattening) of emotions, which was observed in $38.64 \%$ of obese patients and in $42 \%$ of patients in the control group and was represented by emotional decline, impoverishment of emotional sensations and manifestations (fig. 5). In this case, the emotional reactions of patients with obesity were characterized by the prevalence of emotion rigidity (29.55\%) and a significantly lower representation of lability (9.09\%), compared to the control group (24\%), at $\mathrm{p} \leq 0.05$. Patients of control group were characterized, along with the flattening of emotions, by a much more frequent representation of emotional lability, which was manifested by the easy occurrence and the frequent change of opposite emotions.

In the structure of mood disorders of patients in the main group, hypothymia (state of reduced mood with a feeling of anxiety, hopelessness, helplessness, depression, sadness) (45.45\%), anxiety (29.55\%) and dysphoria (29.55\%), the latter in obese patients was markedly more frequent, compared with the control group (14\%), with $\mathrm{p} \leq 0.05$ (fig. 6). In the patients of the control group, anxiety (40\%) and hypothymia (38\%) prevailed in the structure of mood disorders. 


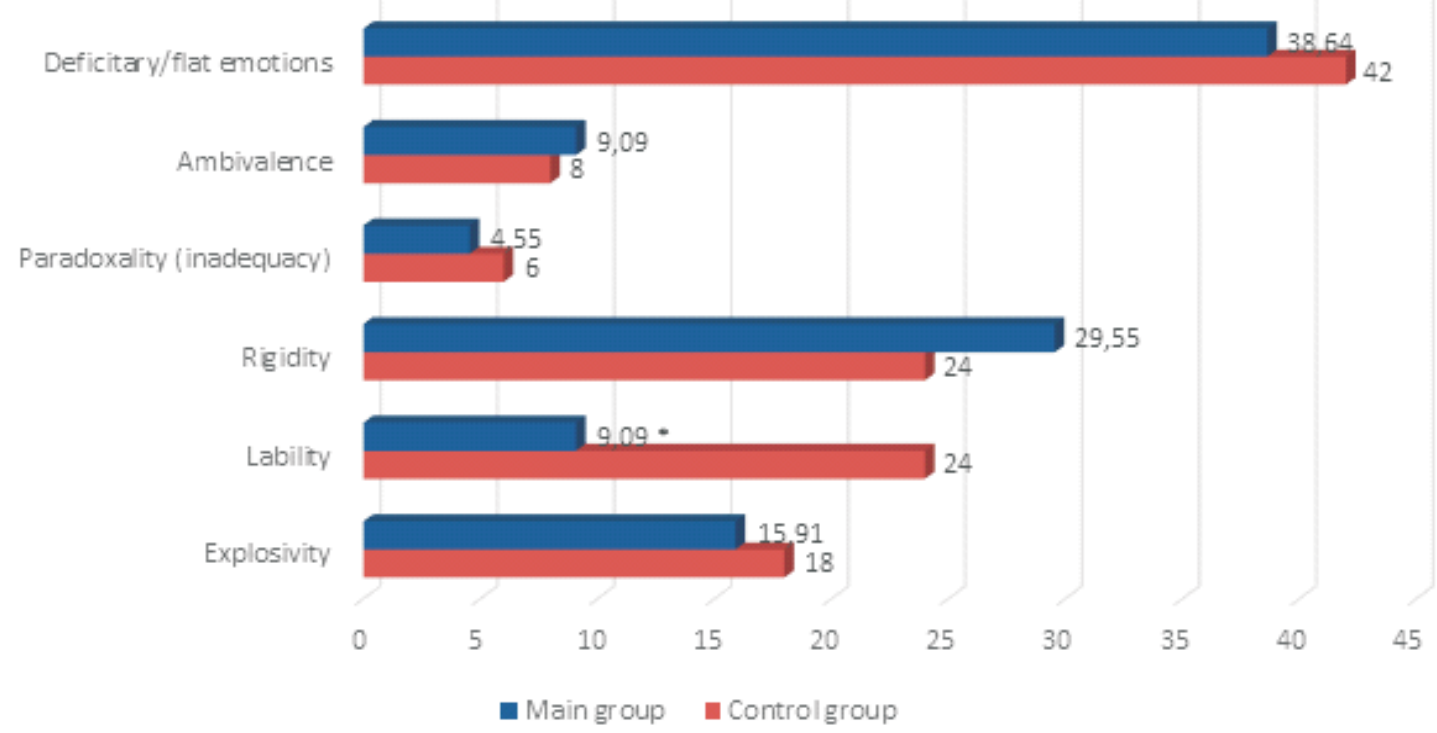

Fig. 5. Disorders of emotional reactions of patients with schizophrenia by the study groups Symbols: *statistically significant differences $p \leq 0.05$

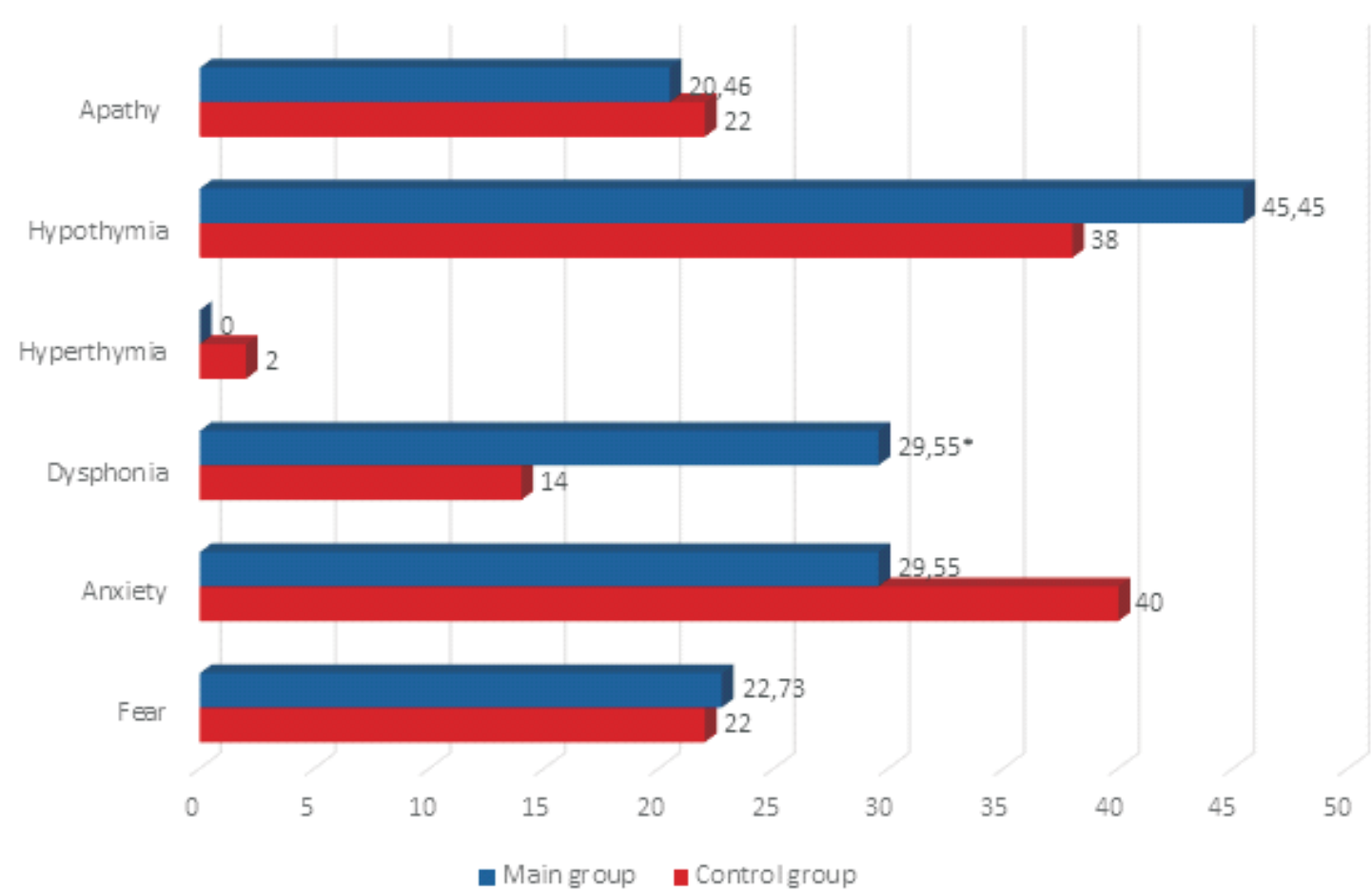

Fig. 6. Mood disorders in patients with schizophrenia by the study groups Symbols: *statistically significant differences $p \leq 0.05$

For the quantitative assessment of the severity of emotional disturbances, the results of the research by the PANSS scale were used, assessing the scales which reflect the peculiarities of functioning in the emotional-will area of patients (table). Disturbances in the emotional-will sphere are represented by subscales that outline the negative $(\mathrm{N})$ and general psychopathological symptoms $(\mathrm{G})$ of PANSS scale.
Among the negative symptoms which determine the emotional functioning in patients with obesity more prevalent emotional withdrawal $(3.24 \pm 0.17)$ was observed in comparison with the control group ( $2.56 \pm 0.12)$, at $\mathrm{p} \leq 0.05$, that were represented with decrease in interest, emotional inclusion and affective participation in life events. Among general psychopathological symptoms $(G)$ in patients with 
Severity of disturbances in the emotional and motivational sphere of patients of research groups according to the results of the PANSS scale

\begin{tabular}{|c|c|c|}
\hline \multirow{2}{*}{$\begin{array}{l}\text { Disturbances in the emotional } \\
\text { and motivational sphere }\end{array}$} & $\begin{array}{c}\text { Main group } \\
\mathrm{n}=44\end{array}$ & $\begin{array}{c}\text { Control group } \\
n=50\end{array}$ \\
\hline & $\mathrm{M} \pm \mathrm{m}$ & $\mathrm{M} \pm \mathrm{m}$ \\
\hline 1 & 2 & 3 \\
\hline N1 Blunted affect & $2.46 \pm 0.14$ & $2.68 \pm 0.12$ \\
\hline N2 Emotional withdrawal & $3.24 \pm 0.17^{*}$ & $2.56 \pm 0.12$ \\
\hline G2 Anxiety & $2.76 \pm 0.16$ & $2.95 \pm 0.18$ \\
\hline G4 Inner tension & $2.1 \pm 0.16$ & $2.4 \pm 0.14$ \\
\hline G6 Depression & $3.65 \pm 0.16^{*}$ & $2.56 \pm 0.14$ \\
\hline G13 Disturbance of volition & $2.25 \pm 0.12$ & $1.86 \pm 0.14$ \\
\hline G14 Poor impulse control & $1.95 \pm 0.14$ & $1.7 \pm 0.12$ \\
\hline Notes: & & \\
\hline
\end{tabular}

the main group, depressive symptoms were significantly higher $(3.65 \pm 0.16)$, compared to the patient from the control group $(2.56 \pm 0.14)$, with $\mathrm{p} \leq 0.05$. Therefore, in spite of the fact that hypothymic mood disorders in obese patients were not represented more often than in patients of the control group, meanwhile, their expressiveness and ability to lead to the depressive state were significantly higher in patients with obesity. In general, the emotional functioning of obese patients was characterized by depressive manifestations and dysphoric mood disorders, combined with emotional withdrawal (reduced or absent emotional interest in events and environments).

Thus, the data of the conducted research indicate that the combination of obesity with schizophrenia is characterized by certain features and specificity of the pathology of sensation and perception, which are manifested in the clinical picture of schizophrenia by the presence of senestopathy and mainly complex hallucinations (which along with auditory and visual include also visceral hallucinations and hallucinations of skin sensation). Emotional functioning of schizophrenic patients with obesity is characterized by rigidity of emotional reactions, the presence of distinct emotional disturbances of the depressive spectrum and dysphoric mood disorders.

The mentioned above reflects the specifics of the clinical design of schizophrenia in the case of its comorbidity with obesity, which should become useful in the development of diagnostic and therapeutic measures.

\section{References}

1. Virshing D.A. (2007) Shizofreniya i ozhireniye: vliyaniye antipsikhoticheskikh preparatov [Schizophrenia and obesity: the effect of antipsychotic drugs]. Sotsial'naya i klinicheskaya psikhiatriya. https://cyberleninka.ru/article/n/shizofreniya-i-ozhirenie-vliyanie-antipsihoticheskih-preparatov

2. Volkov V.P. (2009) Somaticheskaya patologiya i prichiny smerti pri shizofrenii [Somatic pathology and causes of death in schizophrenia]. Zhurnal nevrologii i psikhiatrii. No 5. P. 9-14.

3. Mendelevich B. D., Kuklina A. M. (2012.) K voprosu o rasprostranennosti somaticheskoy patologii sredi patsiyentov, stradayushchikh psikhicheskimi rasstroystvami [To the question of the prevalence of somatic pathology among patients suffering from mental disorders]. Kazanskiy meditsinskiy zhurnal. V. 93, no 3. - P. 532-534.

4. Mosolov S.N. (2001) Shkaly psikhometricheskoy otsenki simptomatiki shizofrenii i kontseptsiya pozitivnykh i negativnykh rasstroystv [Scales of psychometric assessment of schizophrenia symptoms and the concept of positive and negative disorders]. M. 238 p.

5. Solov'yeva Ye. (2010) Ozhireniye u patsiyentov s tyazhelymi psikhicheskimi rasstroystvami [Obesity in patients with severe mental disorders]. Neyronews. Psikhonevrologiya ta neyropsikhiatriya. No 8 (27). https://neuronews.com.ua/ru/issue-article-403/ 
6. Sinayko V. M., Zemlyanitsina O. V. (2010) Rol' neyroleptichnoii terapii u rozvitku metabolichnogo sindromu u khvorikh na shizofreniyu (oglyad literaturi) [The role of neuroleptic therapy in the development of metabolic syndrome in patients with schizophrenia (literature review)]. Arkhiv psikhiatrii. V. 16, no 2 (61). P. 175-181.

7. Cohen A. (2017) Addressing the problems of comorbidity between mental disorders and major non-infection diseases // World Health Organization. 44 p. /http://www.euro.who.int/ru/publications/ abstracts/addressing-comorbidity-between-mental-disorders-and-major-noncommunicable-diseases-2017

8. Druss B., Reisinger E. (2011) Mental disorders and medical comorbidity. Research synthesis report. No 21. P. 21-24.

9. Tandon R. (2013) Medical comorbidities of schizophrenia. Digest of Psychiatry. Vol. 42, no 3. P. 51-55.

10. David J. Castle, Peter F. Buckley, Fiona P. Gaughran (2017) Physical Health and Schizophrenia. Oxford University Press. 136 p.

Received: 10-Oct. - 2018

Accepted: 19-Dec. - 2018 